Discourses of Friendship between Heterosexual Women and Gay Men: Mythical Norms and an Absence of Desire ${ }^{1}$

Gay men and heterosexual women may share some common interests in critiquing heteropatriarchy. However feminism and gay liberationist politics do not always coincide and the role of individual subjectivities in recognising oppressive discourses of normativity remains debated. Interviews were conducted with seven friendship dyads of heterosexual women and gay men. Transcripts were subjected to discourse analysis, which suggested extensive management of heterosexist norms in the friends' accounts of friendship. The analysis highlighted ambiguity over the 'male'status of gay men, a concern with constructing the friendships as legitimately asexual, and the use of parody in the face of homophobia to disrupt normative assumptions. Although we primarily considered the role of heterosexist discourses, there is also evidence that other dimensions of non-normativity (for example, gender and ethnicity) are implicated in friendships constructed around shared otherness and mutual nonnormativity.

Key Words: discourse analysis, feminism, friendship, gender, normativity, queer theory.

In 2003, the UK edition of Elle magazine featured an article warning women about the potential hazards of spending too much time with their gay male friends. Entitled 'Help! I'm a Gay Man Trapped in a Woman's Body', the title parodies a discourse of transgender by juxtaposing a woman's body against a supposedly gay male interior. The article problematises the amount of time some women spend with gay male friends, suggesting this causes them to become more like gay men and to consequently become unattractive to heterosexual men, thus diverting them from the

\footnotetext{
${ }^{1}$ This paper should be cited as follows:

Shepperd, D., Coyle, A., \& Hegarty, P. (2010). Discourses of friendship between heterosexual women and gay men: Mythical norms and an absence of desire. Feminism \& Psychology, 20, 205-224.
} 
normative path of heterosexuality. The article ends with a checklist of symptoms which, although tongue-in-cheek, expresses certain anxieties about the ways in which heterosexual femininity should be performed. Among the signs are:

'Hearing Judy Garland sing Somewhere over the Rainbow never ceases to make you burst into song, if not tears'; 'You can re-enact the dance routines (and do it with pride in public) to every Bananarama song from the 80s'; 'You flirt outrageously with every gay man you meet. But when it comes to straight men your bitchy one-liners are more fag hag than sex siren'; 'Friends comment on your resemblance to Leader of the Fag Hags, Karen, from Will \& Grace'; 'You kid yourself that your penchant for feather boas, crimson lips and an over-abundance of sequins is endearingly flamboyant and eccentric. But that straight guy you're eyeing up is probably assuming you're an ageing stripper. Or, worse still, a drag queen’ (“Help! I’m a Gay Man Trapped in a Woman’s Body,” 2003: 132).

Aside from the crude caricature of gay men, the advice seems to be that readers should be more interested in heterosexual men and keep flirting with them. Women should also avoid identifiably camp culture (e.g., Judy Garland and Bananarama) and eschew make-up that exaggerates femininity when this risks misidentification as a drag queen. The article is unusually overt in its expression of gender norms and regulation of women, femininity and adherence to compulsory heterosexuality. In the main article, a discourse of moderation permits women a limited amount of time spent with gay friends, but suggests that their influence/exposure should ultimately be sublimated to the more important goal of having a heterosexual relationship.

The Elle article draws upon a number of media constructions of friendship between heterosexual women and gay men, most obviously the television comedy Will \& Grace (first screened in 1998). The last decade has seen the emergence of gay male and heterosexual female friendships as a 'new' public phenomenon; they were previously unrecognised by straight culture or dismissed with the 'fag hag' label (Quimby, 2005). Along the same lines as scholarship charting the invention of homosexuality as an identity only in the late $19^{\text {th }}$ Century, despite same-sex behaviours always existing (D’Emilio, 1983; Weeks, 1981), we suggest that although friendships between heterosexual women and gay men have previously existed, this representation 
of 'normal' and mutually rewarding friendship is relatively new. This recent public construction of a meaningful affinity between heterosexual women and gay men (most obviously through their shared sexual interest in men) and an identifiable 'type' of friendship is reflected in the Elle article.

Despite a considerable media engagement with (and construction of) this phenomenon, psychology has largely focused upon heterosexual friendships (Rose, 2000). Indeed studies of cross-sex friendship almost invariably assume the existence of a sexual component (Werking, 1997), whereas sexuality is seldom considered in the context of same-sex friendship (Rose). Consequently the focus of friendship research has tended to be heteronormative, systemically denying the legitimacy of behaviours and identities that operate outside the heterosexual norm (Kitzinger and Perkins, 1993).

This paper challenges this dominant focus within psychology, by considering friendships between gay men and straight women. Feminists have long debated the extent to which gay men's political interests coincide with their own (Jeffreys, 2003). While women and gay men may share a joint purpose in resisting heteropatriarchy (Richardson, 1996), it cannot be assumed that all gay men have investments in feminist politics, or that all women are gay liberationists (or even feminists). According to some feminist positions, gay men are complicit in the oppression of women (e.g. through the fashion industry) and are ultimately more invested in men than in women (Jeffreys, 2003). Furthermore, even political allies may inadvertently reproduce problematic discourses of normativity.

Therefore, rather than focusing on the nature, purpose and meaning of those friendships, we are interested to consider the way heteronormativity appears to be oriented to in the ways gay men and straight women talk about their friendship. We are interested heteronormativity because heterosexual women and gay men may be subjected to different kinds of regulatory powers. The Elle article suggests that heteronormativity operates by limiting the degree of women's friendships with gay men. It expresses anxiety that explicitly non-heterosexual relationships between men and women threaten heterosexuality. What is not apparent is whether this is an empty threat or whether it has some discursive power which works to undo heteronormativity. 


\section{Normativity and subjectivity}

Lorde (1984: 589) recognises that normativity is multifaceted and identifies what she calls 'the mythical norm': the 'thin, white, male, young, heterosexual, Christian and financially secure' individual (we could continue adding dimensions of normativity). A multifaceted approach highlights the possibility of intersections between different axes of (non-)normality (e.g. androcentrism, ethnocentrism and heteronormativity): people can be subjected to multiple oppressions or simultaneously occupy both privileged and disadvantaged positions. This highlights a relationship between the identities people inhabit and the types of norms speakers might or might not flag up. Lorde argues that we attend more to critiquing those norms that adversely affect us, than to the ways we may be privileged. Although there may be some shared understanding of norms implicit in culture, some aspects are more salient for certain people, at particular times. Crucially, this means we may fail to adequately articulate oppressions that do not impinge upon our own identities.

Although some identities may obscure or ignore others, certain norms (although prevalent) are not obviously 'norms' until exposed as such (Jeffreys, 1991). Most theories of human relations are based upon an implicit model of heterosexuality. However this norm is often hidden from view because it is so dominant, meaning heterosexual culture 'interprets itself as society' (Warner, 1993: xxi). One 'real world' enactment of heteronormativity is the structuring of public spaces (like hotels) as instantiations of heterosexuality. For instance, lesbian couples booking hotel rooms face a disclosure dilemma over whether to ask for twin beds or a double (Valentine, 1993), a potentially difficult situation produced by heteronormativity, but one which would not be obvious to many heterosexuals. Thus the norm is essentially invisible to the larger portion of society that benefits from its operation.

Queer theorists like Warner (1993) regard implicit norms as exercising regulatory power, and focus on critiquing norms as a concept. Butler (1990) tried to expose the illusion of heterosexuality as inevitably 'normal' by suggesting that heteronormativity is produced through a continual process of construction. This radically reverses how we think about gender and sexuality: Instead of identity being the outward manifestation of an inner state, Butler argues that performance is the cause of gender or sexual identity, not the product. Consequently there is no original expression of heterosexuality, only reiterations of an imagined natural heterosexuality; therefore homosexuality cannot be an 'inferior' version of heterosexuality (see 
Nentwich, 2008, for further discussion). This argument challenges claims of naturalness that privilege certain genders or sexual identities. Butler (1993) suggests that disrupting and denaturalising normative genders, through the use of parody and drag, can reveal gender as a construct. There are concerns about how practical Butler's idea of parody might be, given audiences' scope for less radical interpretations. Richardson (1996: 8) questions how the supposedly transgressive use of a dildo as a 'lesbian cock' is supposed to challenge heterosexuality as an institution, given that it is likely to be interpreted as an imitation penis (see Lamos, 1994). So although there may be good cause to disrupt and call attention to norms, it is not always obvious how to avoid the problems of heteronormative re-appropriations of queer interventions into sexed and gendered being. Consequently it may be difficult to anticipate which parodies successfully challenge norms and which fail.

\section{Normative relationships}

With these concerns in mind, we turn to instantiations of norms in friendship. Not only are men and women expected to be sexually involved with one another, but nonsexual relationships often have difficultly justifying themselves as psychologically important. The very word 'relationship' normatively means 'sexual relationship' (Kitzinger and Perkins, 1993). Almost inevitably this prioritises sex and relegates other aspects of relationships to a lower category. 'Sexual acts are burdened with an excess of significance' (Rubin, 1984: 279), yet the absence of sexual behaviour can also call attention to itself. Sandfield and Percy's (2003) work on the discursive devices employed by unattached women in accounting for their single status suggests that heteronormativity produces awkward moments, not just for same-sex couples, but for anyone outside of the normative heterosexual model. Friendships are treated less seriously than romantic relationships by the general public, by social scientists, and by society: friends (even those who cohabit) have few legal privileges to compare with those in state-sanctioned sexual relationships (Rose, 2000). Thus, norms not only privilege certain types of sexual relations, but also structure other non-sexual relationships by positioning them as secondary.

In this paper we investigate the ways that accounts of gay male/straight female friendships can both be read as discourses of, and resistance to, sexual normativity. Normativity provides a lens through which we understand the negotiation of differences between gay men and heterosexual women. Using interview data, we 
consider how the friends co-constructed and contested accounts of performance (and parody) of gender roles. We wanted to better understand the complexities of how they negotiated a performance of sexual identities, given the potential for both overlapping and oppositional political interests.

\section{METHOD}

The analyses in this paper draw upon interviews conducted with seven pairs of gay men and heterosexual women in south east England. We recruited participants through pre-existing social contacts (i.e. friends of friends) and via internet sites (e.g., gaydar.co.uk and outeverywhere.com). We contacted five dyads through the male friend and two via the female friend. Interviews took place in one of the participant's homes in all but one instance (which took place in a university interview room).

The 14 participants were aged 21-64. Nine were White British, one White Irish, one Iranian, one Mixed Caribbean, one British-Chinese and one Asian/Portuguese. We deliberately sought participants with a variety of careers and educational backgrounds: participants included an artist, a makeup artist, a graphic designer, a retired builder, a student, an office worker, an account manager, a personal assistant, a public relations worker, two school teachers, a retired solicitor and two university lecturers. We do not provide specific demographics for particular participants in order to preserve anonymity.

Each pair of friends consented to an in-depth, semi-structured joint-interview with DS. The interview schedule focused discussion on the history of their friendship and specific milestones during its development. It was structured to follow a narrative course, from friendship formation, through problems and ending with aspects of the friendship that they valued most. Interviewees were asked to talk about some of the milestones and challenges, as well as current aspects of their friendship. In practice, much of the content and structure of the interviews was determined by the participants' negotiation of matters of importance within their friendship stories. Interviews typically lasted between 1.5 and 2.5 hours and were transcribed according to a simplified version of Jefferson's (2004) system. Although our analysis here is not dependent upon such a detailed form of transcription, it represents the participants' talk in interviews more faithfully, and readily equips other analysts to scrutinise our data and consider our interpretations. 
The transcripts were subjected to discourse analysis, which allowed us to attend to points of apparent contradiction and variability. We adopted a social constructionist epistemology (Burr, 2003) and focused on how each dyad coconstructed an account of their friendship by utilising culturally available discourses of friendship, gender and sexuality. The analysis drew upon what has been termed 'Foucauldian discourse analysis' with a focus on discursive resources and their implications in terms of power and ideology (see Parker, 1992), while also attending to the more micro-level analyses favoured by discursive psychology (Edwards \& Potter, 1992). This integrated approach has been best exemplified by Wetherell's (1998) critical discursive psychology, which argues for a post-structural analysis that takes account of culturally available extra-textual systems of meaning, as well as more micro-interactional processes.

The transcripts were read repeatedly and coded for identified themes. We identified connections and contrasts, resulting in three distinct topics: 1) discourses of normativity; 2) commodification of identity; and 3) discourses of liberalism. The first of these is discussed here. Specific examples of normativity were collated and those which were more detailed or expressed ideological tensions/dilemmas were subjected to closer analysis. Specific discursive and rhetorical features were identified and their action orientations (i.e. how discursive resources are used and to what effect, Willig, 2001) discussed in the light of feminist and queer readings of normativity.

At points in the transcripts, micro-textual analysis of speakers' utterances suggested ways that they oriented to and managed the interview context. Claims about the 'artificiality' of this context have occasioned a move away from research interviews within discursive psychology and towards 'naturally-occurring data' (see Potter \& Hepburn, 2005). Participants in the present study could be seen to orient to the 'demand characteristics' of the interview to provide a convincing account of their friendship. They reported that they had not previously discussed many of the issues raised in the interviews and constructed themselves as interpreting the meanings of their friendship in a more direct way than they had done previously. The transcripts routinely contained features associated with impromptu account negotiation and thus provided insights into the resources and moves that members of these friendship dyads may employ in working up occasioned accounts of their friendship. The ways in which these overlap with, or differ from, data produced by gay male-heterosexual 
female friendship dyads in other contexts of friendship talk are a matter for further investigation.

The following analysis is intended to offer one possible interpretation of the interview data. However, we explicitly want to call attention to the way that the authors (as three gay men) have attended more to heteronormativity than sexism. This is not to suggest that we regard sexism as politically unimportant, but rather, as Stokoe and Weatherall (2002) suggest, that analysts inevitably bring their sexual politics to the selection and interpretation of data. Where participants have oriented to the interviewer's sexual identity, we have tried to analyse that talk without privileging the interviewer's identity as beyond interpretation or 'neutral'.

\section{ANALYSES}

In these analyses, we examine the role of non-normative sexuality in excluding gay men from normative masculinity. We also discuss the implications of heteronormativity for gay men, heterosexual women, and for friendships between them. Management of other people's perceptions of the interviewees' friendship will be considered with particular references to the use of parody and other means of disrupting normativity. Lastly we consider whether difference from Lorde's (1984) 'mythical norm' can itself become a basis for friendship, such that non-normativity can be a form of affinity.

\section{Normativity and Gay Men}

Many of the participants (mostly women) drew upon accounts of psychological sex differences to explain the importance of their friendship. In this extract, Emily explained that her friend Mike gave her a male perspective that (by implication) her female friends could not provide ('I' denotes the speaking turns of the interviewer, DS).

\section{Extract 1}

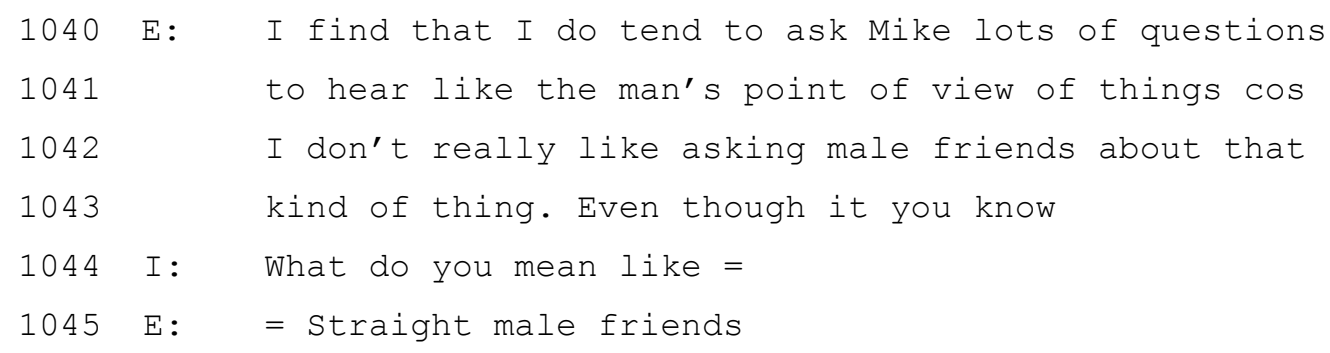




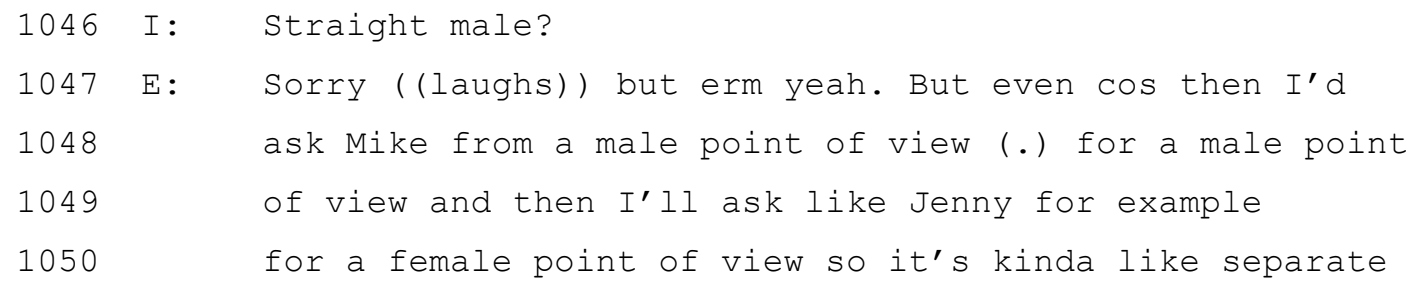

Here, 'difference' needs to be understood and Emily suggested that she was curious about the alternative (male) viewpoint. This spoke to a binary gender discourse where masculinity is a communicable and unified experience that Mike was apparently able to articulate on behalf of all men. Indeed later Emily reported asking Mike about the male gaze: 'I was getting a bit jealous of my boyfriend staring at other women and stuff and I was like saying to Mike is that quite normal for you know men to do?' (lines 1243-6).

Masculinity and femininity were constructed as essentially separate, with Emily able to ask Mike and Jenny for their gendered (and, from Emily's perspective, 'objective') opinions. Yet in voicing her difficulties in talking to men, Emily excluded Mike from the category of 'male friends' (line 1042), shifting between accounts of 'men' that included and excluded gay men. When the interviewer started to query this account, she quickly repaired the construction and apologised with a laugh. The repair suggests that Emily became aware that she was hearable as having constructed Mike as 'not male'. The slippage between 'male' and 'straight male' exemplifies one form of heteronormativity that Braun (2000) sees as heterosexism by commission (an articulation of heterosexist assumptions). The interviewer's interjection disrupted her construction and she immediately identified the norm she has drawn upon. Emily modified what she was seeking to 'straight male', yet rather paradoxically Mike was then re-positioned as able to offer her this vantage point despite being gay.

Like the media discourse of Will \& Grace, Emily seemed to be suggesting that Mike's gay identity permitted her to speak to him in ways she could not with heterosexual men (apparently including her heterosexual boyfriend). This publicly available account is something that Emily drew upon as she constructed the value of their friendship. Emily later raised the potential for a special kind of friendship between heterosexual women and gay men, which she constructed in terms of the problems of mixed-sex friendships. Yet, as Extract 2 shows, Mike was wary of the idea that gay men should be inherently preferable friends for straight women: 


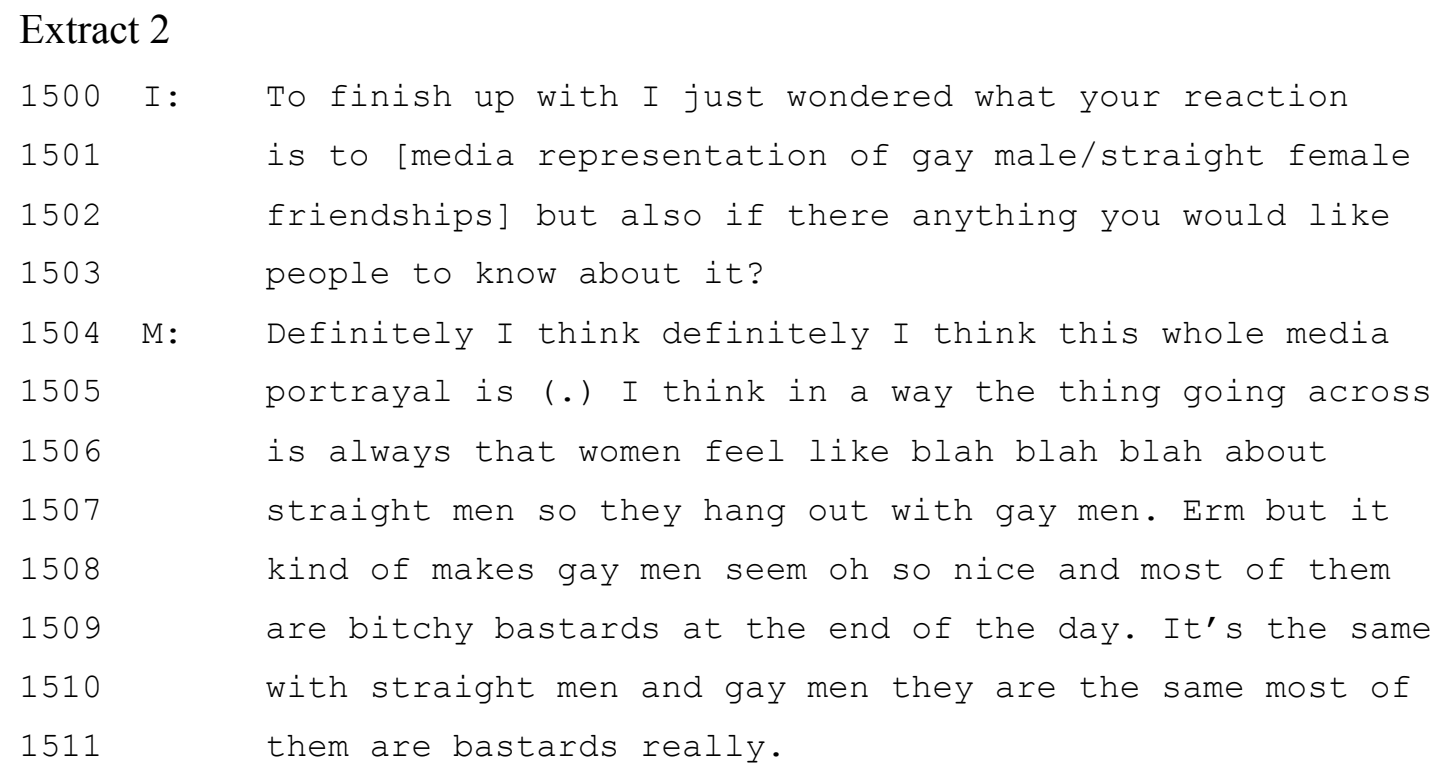

Mike can be seen to reject a positive representation of gay men as sensitive and 'oh so nice' (line 1508). He resisted the discourse of allegiance between gay men and heterosexual women, then introduced a bottom-line argument that 'most of them are bitchy bastards at the end of the day' (lines 1508-9). Mike qualified this with the word 'most' (lines 1508 and 1510) but nevertheless appealed to a sense of universality amongst 'most' men and suggested that they are essentially all the 'same' (line 1510). There was, however, some variability in how he treated gender. Firstly gender was prioritised: unlike Emily's earlier construction, gay men were first and foremost men. However the construction of 'bitchy bastards' coupled two oppositely gendered insults. This speaks to a discourse of gay men which associated them with effeminacy, yet also claimed masculinity. It also resonated because the lexicon of sex role slang is wider for gay men (accounting for 35\% of terms) than for heterosexuals (7\%) showing gay men's marginal status compared with hegemonic heterosexuality (Peel, 2005). In embracing a construction of gay men as potentially not so 'nice' without providing any stable, easily categorised alternative, Mike implicitly resisted Emily's construction of interactive possibilities that are not available in exchanges with straight men.

In the first extract we presented a construction, albeit perhaps unintentional, of gay men as sufficiently non-normative that they are (temporarily) excluded from the category of men. Conversely gay men are positioned as able to represent a generic male perspective and, in the second extract, Mike's condemnation of gay men is partly based on their similarity (albeit bitchy) with straight men. The normativity of gay men 
seems variable and perhaps, if we return to Lorde's (1984) mythical norm, mediated by the speaker's identity.

\section{Disrupting Norms}

If positioning gay men as nice non-normative men results in the self-interpolation that gay men are 'bitchy bastards', what else can people do apropos of normativities? In this next extract, the participants interrogated normative sexuality. Querying Butler's (1990) notion of parody and the lesbian phallus, we examine an account which exemplifies some of the ambiguities around passing and parody. Cerys and Rob coconstructed a narrative around a holiday they spent together some years previously where a shared bedroom produced the potential to 'out' Rob.

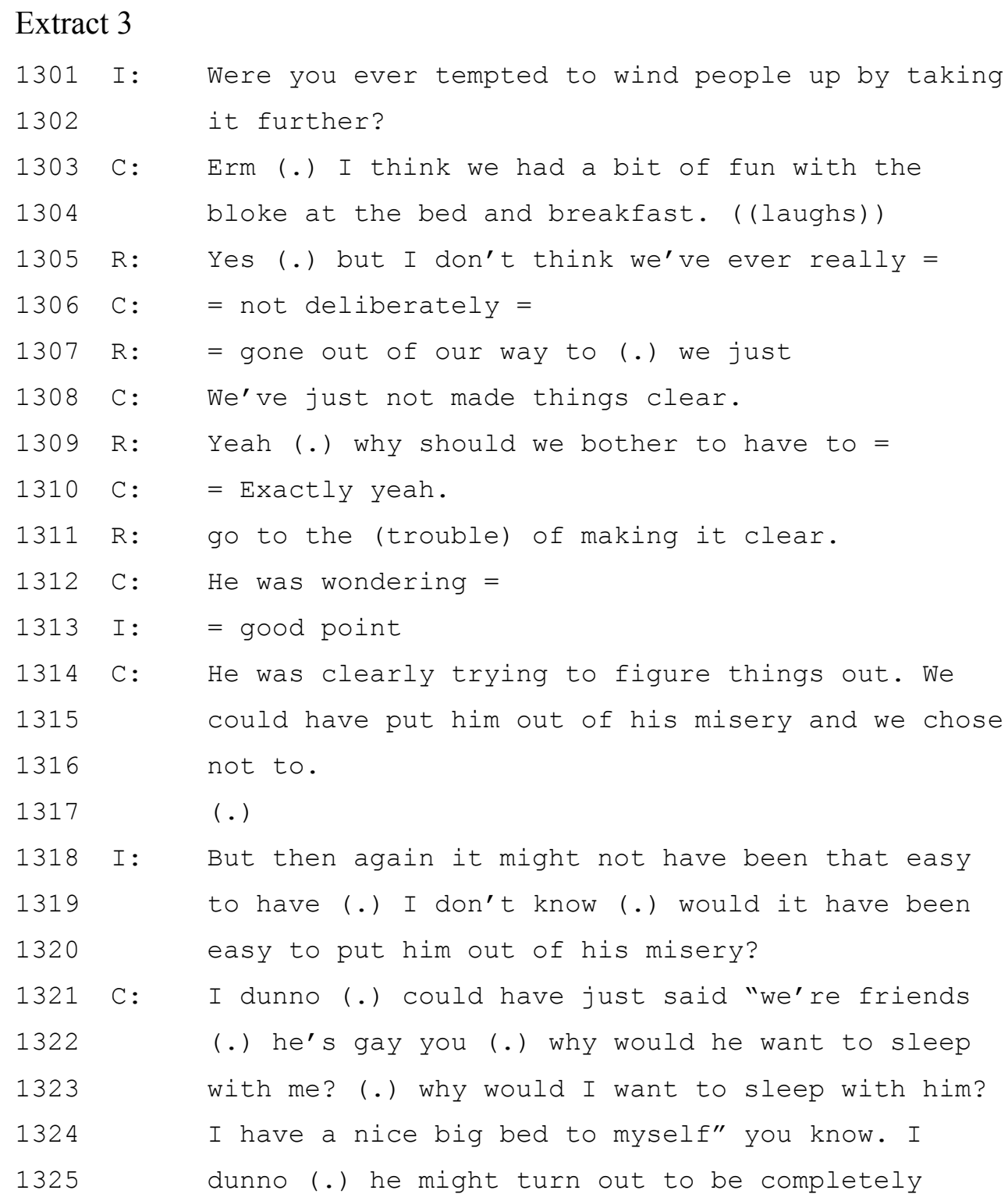




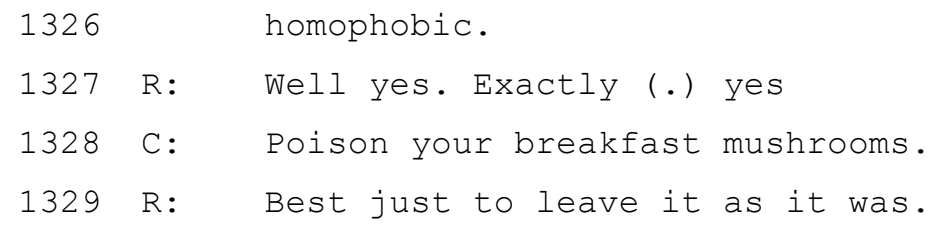

In their account, while staying in 'bed and breakfast' style accommodation, they shared a room with multiple beds. The puzzled owner was reportedly unable to reconcile Cerys and Rob sleeping in different beds with them not having fallen out or argued. They superficially had the raw ingredients for heterosexuality and so Cerys voiced a perceived expectation that they should be sexually involved.

Like Valentine's (1993) observation of the heterosexism experienced by lesbians checking into hotels, gay men and heterosexual women on holiday together are also read in heteronormative terms. This requirement to explain themselves and their non-normativity was not lost on Rob and he questioned 'why should we bother to have to [...] go to the (trouble) of making it clear' (lines 1309-11). This shifted the responsibility away from them as actors; it was not necessarily their role to correct every misreading of their relationship.

Rob queried the assumption that they should have to explain their friendship and this resonates with queer theorists' (e.g., Butler, 1990) rejection of normative categories (instead of engaging in a liberal-humanist struggle for acceptance). Yet the assumption produces a 'double bind' where silently passing as heterosexual confirms the taken-for-grantedness of heterosexuality, but coming out is not only risky but also acknowledges the hegemony of heterosexuality.

The interviewer asked Cerys and Rob about their role in permitting this (mis)reading of their relationship to be perpetuated and the notion of 'winding up' (line 1301) introduced the possibility that they were actively misleading the hotelier; producing a scene to be gazed upon. Cerys' idea that this performance was a 'bit of fun' (line 1303) disclaimed the significance of their actions, heading off an alternative interpretation that they were trying to embarrass the hotelier. They deflected claims that they have done something dishonest, which makes it hard to then claim they have made a political statement. Yet their account reclaimed as fun a situation where sexual normativity had the potential to disrupt their holiday.

Cerys offered a hypothetical example of how she could explain their relationship to the hotelier. She gave a number of reasons, not for why they are friends 
but for why they are not in a romantic relationship. 'He's gay you (.)' (line 1322) raised the questioner's knowledge (through the assumed but unspoken 'know' after the momentary pause) into the discourse as well as Rob's sexuality. Suddenly the hotelier appeared to be someone who should 'know' not to presume heterosexuality. Firstly Cerys treated it as an easy speech act to make before orienting to homophobic consequences. In the next part of Cerys' justification of their friendship, she said 'Why would he want to sleep with me? (.) why would I want to sleep with him?' (lines 1322-3). The balancing of this couplet emphasizes their mutual lack of sexual desire and headed off any suggestion that she might (secretly) desire him. It spoke to a discourse of 'compulsory heterosexuality' (Rich, 1980) and their need to justify not sleeping together. His gay identity was used to explain the non-normative absence of sexual interest.

Up to this point, neither Rob nor Cerys attended to the reaction they might encounter in such a situation. The interviewer's question about how they would raise the matter hinted at the possibility of difficulties but Cerys was the first to explicitly mention a hostile response, saying 'I dunno (.) he might turn out to be completely homophobic' (lines 1324-6). At this point Rob took up the conversation saying, 'Well yes. Exactly (.) yes' (line 1327). Rob's gay identity gave him the entitlement to speak with expert knowledge and confirmed her speculation as a real possibility.

In reading this extract, we become aware of how each speaker has different stakes in the matrix of sexual norms. In the interview Cerys was able to parody homophobia with an ironic reference to 'Poison your breakfast mushrooms' (line 1328) - hardly a typical homophobic attack. Meanwhile Rob's reaction may suggest a connection between his identity as a gay man and his more sober articulation of the threat.

The way that we interpret this account greatly depends upon our own theoretical positions: some queer theorists might see this as parody in a Butlerian sense with some subversive potential, whereas some feminists might see passing, closeting and recapitulation. This example seems to fall between the theoretical categories of parody and performance and refuses to be classed in any sustained way, suggesting that feminist and queer theories may be harder to tease apart when considering 'real' social interactions.

In the next extract, two interviewees talked about their engagement in a more overt parody of heterosexuality by kissing, and appeared to use this to combat 
homophobia. A widespread theme in many interviews was the problem of friendship and desire coexisting. Given the cultural currency of this discourse (c.f. Werking, 1997) it is not surprising that the pairs of interviewees invested considerable discursive resources in asserting the absence of sexual tension. The normalcy of heterosexual desire between 'men' and 'women' is such that participants' accounts drew heavily upon gay sexuality to explain the absence of attraction. In discourse, gay sexuality operated as an effective blockade against the possibility of desire, to the point where heterosexual behaviour was openly practiced between gay male and straight female friends without constituting evidence of inner psychological desires.

\section{Extract 4}

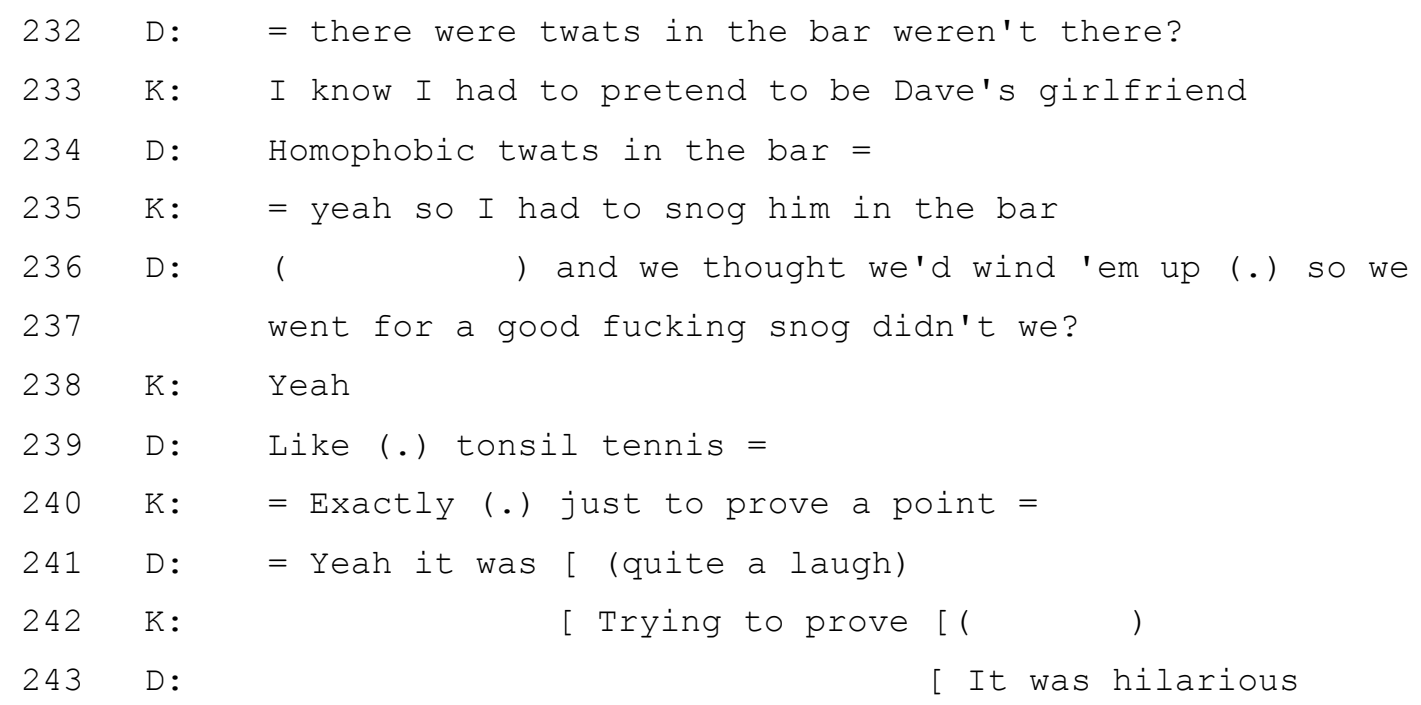

This story explained how they aimed to 'wind up' the (presumably heterosexual) 'homophobic twats' (line 234). It suggested considerable pleasure at making available a potential misreading of their relationship and thus confusing the 'homophobic twats" initial assumption. Its humour is also based around a parody of heterosexuality that excluded the 'homophobic twats' by winding them up. Considerable discursive work was involved in heading off alternative readings that the 'snog' represented sexual desire: having set the scene and outlined a socio-political motive for the 'snog', Katie explained it was 'just to prove a point' (line 240) thus denying other motivations and Dave added that it was 'quite a laugh' (line 241) which he upgraded to 'was hilarious' (line 243).

Their account of the 'snog' is rendered more possible by the social circumstances in which it took place; the catalyst of the homophobic abuse and the 
public context. A 'good fucking snog' (line 237) in private or in other public settings would mean something different. The presence of the 'homophobic twats' (line 234) purged the act of desire, allowing the event construction as a parody of heterosexuality, where they did something normative in a queer or non-normative way. However, as noted earlier, parody may be interpreted as 'reality' (Richardson, 1996), and so has the potential to be politically counter-revolutionary. This raises questions about the extent to which Dave and Katie's performance troubled the heteronormativity of the 'homophobic twats' in the bar. Yet, unlike in the previous extract, we see that Katie and Dave were constructing a powerful political manoeuvre in a specific environment, thus giving us a much stronger sense of parody. We can not know how it was read by the 'homophobic twats'; in the narrative, it appeared to have empowered Dave and Katie at a moment of oppression. But, if it did so, was this achieved by only obscuring Dave's gay identity? Perhaps individuals have greater difficulty bringing off performances as parody than the more theatrical queer collective actions (e.g., 'kiss-ins') that Butler advocated.

What seems more troubling within this account of parody is Dave's sexist use of the word 'twats' and 'homophobic twats' (lines 232, 234). Possibly he was parodying homophobia but used a gendered insult to do so, parodying along one dimension, whilst invoking problematic norms along the other. Yet unlike Emily's slip in the first extract (where she excluded Mike from the category of men), this utterance went unchallenged by the gay male interviewer. Furthermore it took the authors longer at the analysis stage to notice this misogynistic construction than the previous heteronormative one. This suggests that, for authors and interviewees alike, certain kinds of situated knowledge are more readily available (and easier to comment upon) than others.

In both these extracts the interviewees discussed instances of 'real' or inferred heterosexism and talked about performing heterosexuality in ways that might confuse or disrupt onlookers' assumptions. In one instance the friendship, and its nonsexual/romantic status, seemed to require explanation and in the other the threat appeared to be directed more specifically at Dave's gay identity. In both cases they articulated strategies that involved elements of parody, yet they are also readable as recapitulation. Although it may not be possible for to gauge the (potential) effects of these performances, they indicate that parody may be more contradictory than queer theorists might suggest. 


\section{Solidarity in Difference}

Issues of normativity were rarely referred to explicitly by participants. Under analysis, the processes of normativity became salient to us but the speakers themselves did not often overtly raise the issue or reflect upon its importance for their friendship. One notable exception concerns Amitis' ethnic minority status and her white friend Paul. She directly drew upon their shared sense of non-normativity to construct them as ethnic and sexual Others.

\section{Extract 5}

\begin{tabular}{|c|c|c|}
\hline 1223 & A: & It was not easy \\
\hline 1224 & & because your language, the way you talk, you use your \\
\hline 1225 & & hand and da da da is very different (.) and back then \\
\hline 1226 & & I was a lot more different (.) because it's at least \\
\hline 1227 & & fifteen years gone. So it's nice because gay men are \\
\hline 1228 & & minority (.) in a sense for me the people who I met who \\
\hline 1229 & & I became very close to because they are a minority \\
\hline 1230 & & within their own society. Some form of difference and \\
\hline 1231 & & being different and actually needing to talk about it \\
\hline 1232 & & (.) and that was a very very very (important) (.) I \\
\hline 1233 & & know for that reason I end up being closer to gay (.) \\
\hline 1234 & & to white gay men in college than than other people. So \\
\hline 1235 & & for me it was and still is that difference. It doesn't \\
\hline 1236 & & matter how much I live here (.) I'm a minority (.) \\
\hline 1237 & & visually and culturally in a way. \\
\hline 1238 & I: & So why do you think people want (.) or need to talk \\
\hline 1239 & & about difference? \\
\hline 1240 & A: & Need to? Erm (.) wow (.) \\
\hline 1241 & $I:$ & I don't disagree with you. \\
\hline 1242 & [Paul' & s boyfriend enters and there is a brief interruption] \\
\hline 243 & $\mathrm{~A}:$ & I think it's partly for your sanity $=$ \\
\hline
\end{tabular}

By evoking gay men as a 'minority within their own society' (lines 1229-30), Amitis did not treat society as entirely monolithic or conflate it with heterosexuality (cf., Warner, 1993). Nevertheless she constructed herself as outside the social group that gay men are 'within' (line 1230), despite their marginalised position. Amitis invoked the idea of intersections between multiple axes of (non)normality that potentially 
compete or work in conjunction with each other. She accounted for her many friendships with gay men in terms of 'needing to talk about' (line 1231) difference and their mutual non-normativity. This speaks to Lorde's (1984: 589) mythical norm of the 'thin, white, male, young, heterosexual, Christian and financially secure'. She seemed to focus on the multifaceted dimensions of normativity and constructed an account of shared experience between different non-normative identities.

Amitis spoke of her time at college where she met many of her gay friends (though not Paul): 'I end up being closer to gay (.) to white gay men in college than than other people' (lines 1233-4). Amitis started constructing an argument that links specific identities through their shared sense of being Other. Her experience of difference seemed to be a process of co-discovery and mutual exploration of what normativity means (lines 1225-7; 1235-7). Among our interviewees Amitis was the most explicit about having political friendships. Her account suggested solidarity or affinity through difference; that being in some way 'Other' to the normative can be a basis for friendship.

The interviewer's question (lines 1238-9) about why people might wish to discuss difference was met with a surprised response. The interviewer clearly oriented towards this, saying 'I don't disagree with you' (line 1241). Amitis' exclamation, 'wow' (line 1240), indicates some amazement that the interviewer even had to ask; perhaps she regarded this as surprisingly naïve coming from someone who should know about difference. From her response, 'partly for your sanity' (line 1243), we get a sense that exploring normativity might have positive effects for well-being rather than simply about making inter-group comparisons. She also suggests a need to interrogate difference rather than treating it as necessarily pejorative. This raises questions about the ways in which others' experience of being non-normative may inform people's subjectivities in ways that they were previously unaware of.

However is there any evidence to suggest heterosexual women and gay men orient towards shared interests in resisting heteropatriarchy? Participants tended not to construct their friendships in overtly political terms, preferring instead discourses of personality. However, there were occasions in which they used the intersection of gender and sexual identities to account for valued aspects of their friendships.

Later in the interview, Paul provided one explanation for why he enjoyed female company saying, 'I just feel more comfortable. There is also no way that we are gonna get drunk and end up in bed together (.) there's not gonna be any of that 
awkward sexual tension and anything' (lines 1261-3). In one sense, this draws upon a model of fixed sexual desire where people only have sex because their 'on-the-record' sexual orientations match up. Since he did not desire Amitis (or presumably any other female friends), there was little likelihood of them having sex. There was nothing to indicate that Amitis was sexually attracted to Paul but nevertheless his construction revolved around male as normatively desirous. It assumes that people only engage in consensual sexual behaviour when both (or all) parties desire each other.

The possibility of having some sort of sex occurring was constructed as most conceivable when it involved alcohol. Drinking here seemed to serve as an explanation for what follows or perhaps even a way of not explaining. Drunkenness opened up a possibility space in which they were able to construct a 'what if' scenario. Notably Paul did not sketch out a situation where he actually desired Amitis or where they decided that sex might be enjoyable regardless of the lack of desire. These would also be potentially problematic possibilities to articulate no matter how hypothetically framed. The very utterance of such possibilities would require considerable rhetorical work to neutralise. Desire between men and women is so normative that any disruption of Paul's gay identity (as perhaps bisexual instead) would make mutual desire possible. We see in this that gay sexuality is constructed in these interview contexts as an absolute. The presence (or absence) of sexual behaviour seems to have the power to fundamentally alter the friendship (Werking, 1997). The rhetorical work needed to avoid treating seriously the possibility of desire speaks to what Jackson and Scott (2004) see as the immense weight placed on sex and how it inexorably (re)defines relationships.

Amitis' explicitly political discourse of friendship attended to the benefits of forging alliances with other non-normative identities. Despite the differences between being ethnically non-normative and sexually non-normative, she oriented to a common exclusion from Lorde's (1984) mythical norm as being an important basis for friendship. Paul meanwhile attended to the expectation of sexual tension between women and men. He highlighted the non-normative absence of sexual desire as a valued feature of their relationship which seems to speak to the primacy of sexual or romantic relationships over mere friendship (Werking, 1997).

\section{CONCLUSION}

In these interactions, no one speaker had the monopoly on discourses of normativity 
or non-normativity: in their accounts, members of each dyad were marginalised in some domains whilst being normative in others. The data presented show examples of a heterosexual woman's exclusion of gay men from normative masculinity and a gay man's unchallenged use of sexist language suggesting that friends may uncritically draw upon normative discourses. Yet we also discussed co-operation between heterosexual women and gay men and the means by which they might use strategies like parody to challenge normative assumptions. Lastly we considered the account of a participant who articulated a desire to coalesce around shared understandings of normativity and her friend who found the freedom from sexual expectations liberating.

Lorde's (1984) suggestion that people are more able to speak about the ways in which they stand outside the mythical norm was borne out by speakers who oriented towards their own marginality and left their privilege(s) more often unspoken. Emily's brief positioning of Mike outside masculinity shows how the interviewer's challenge drew attention to the norm and she made a rapid repair. This demonstrated the seemingly unintended use of heteronormative gender categories by a speaker who was positioned as 'gay-friendly' by the data analysts (and who undoubtedly positioned herself thus in pre-interview interactions). We might wish to consider this as an example of the discourse speaking the subject rather than as some reflection of Emily's 'true' inner-state. Instead of the speaker being in a position of absolute authorship, we see them using a collage of pre-existing discourse which produces a moment of heterosexism by commission, spoken by a 'liberal' person (Braun, 2000).

The pro-gay discourses taken up by Emily met with some resistance from Mike who queried the account of gay men as somehow preferable (to straight). Similarly Cerys broadly supported disclosing Rob's sexual identity but he questioned the imperative to come out. Whilst not worked up as an explicitly queer critique, they do nevertheless point to tensions between gay-affirmation and outright rejection of normative categories. Nevertheless discourses of co-operation did emerge. Dave and Katie's 'parody kiss' was certainly presented as disrupting the "homophobic twats" positioning of Dave, yet we cannot know whether it was interpreted as 'straightening' Dave or queering heterosexual behaviour. Although this is partly an epistemological concern, it also suggests difficulties with authoring queer performances in 
heterosexual spaces. The public performances Butler (1990) advocates involve collective action rather than individual gestures. Lloyd (1999: 197) points to a shift that occurs between Gender Trouble (Butler, 1990) and Bodies That Matter (Butler, 1993), highlighting Butler's disavowal of the subject as an 'autonomous agent' and an emphasis upon reiteration to produce the subject. This means individual parodies may be limited in their transgressive effects, because they are more easily subsumed as imitations of heterosexuality. Diamond's (2005: 104) analysis of media representations of female same-sex sexuality suggests that performances of 'heteroflexibility' are seldom seen as challenging heterosexuality. We also know nothing of the physical performance of the kiss and whether aspects of embodiment invite a queer reading to on-lookers. It is, however, possible that their effects lie more in the way they disrupt normative assumptions of friendship than in changing perceptions of Dave's sexual identity.

Unlike the hypothetical lesbian phallus (Butler, 1993), these actual cases are rather fuzzy in their politics. Thus we might identify parodic potential in a public 'snog' but also see elements of recapitulation and heteronormativity. Dave's use of sexist language, to describe anti-gay people, is an instantiation of norming in a relationship that is frequently positioned as non-normative (or even radical). The inevitable reproduction of norms in friendship is something we might have anticipated at a theoretical or implicit level, but here we have empirically supported something feminist scholars (e.g. Frye, 1983; Jeffreys, 2003) have long suspected.

The politics of parody are not easily resolved: ordinary events (e.g., playing a joke on holiday) are much more nuanced than in the imaginations of theorists, and so frustrate the categories of analysts. Whilst some scholars treat parody as an irreconcilable difference between queer theory and feminism (Jeffreys, 2003), our data suggest that people living out these friendships move between inhabiting preexisting discourse and parodying or troubling those same discourses when collaboratively producing narratives.

Amitis was explicit about the way she embraced difference as shared Otherness. Non-normativity was to be experienced and explored rather than annexed. This suggests that although Otherness tends to be a source of oppression and nonnormativities can manifest specific sets of identity politics (Jeffreys, 2003), there are 
also ways that people may coalesce around a shared critique of normative values which we might recognise as an objective of queer theorists (Jagose, 1996). In the case of Amitis and Paul, it became clear that she constructed non-normativities as roughly equivalent, not in the sense that they are identical, but as all being a basis for political affinity. This suggests the need to consider friendships not just in terms of commonalities, but also in the sense of affording forms of political solidarity between identities based on shared non-normativity.

Sexual norms manifest themselves not just in sexual relationships (Kitzinger and Perkins, 1993) but, as we see here, in explicitly non-sexual friendships. The expectation that emotionally close men and women should be romantically and/or sexually involved (Werking, 1997) is at odds with the normative form of friendship as non-sexual (Rose, 2000). This produces a culturally available discourse which reads friendships between men and women as potentially problematic because of sexual tension (Nardi, 1999). The accounts that these speakers produce emphasise the absence of sexual tension, suggesting these friendships are important because they are sexually uncomplicated. Whilst this seems to offer valuable opportunities for mixedsex friendship and a source of emotional and political solidarity, the emphasis placed on the absence of sexual desire risks implicitly sanctioning the norm of desire in mixed-sex heterosexual friendship.

Before reaching our concluding comments we want to consider how research design and practice may have impacted upon the results. Recruitment of dyads occurred predominantly through the gay men, with the heterosexual women brought in subsequently. Ideologically, this was undesirable because it reproduced the primacy of men, but it also created situations where gay participants had a number of heterosexual women friends, any one of whom was potentially a suitable interviewee. Of course not all social networks collapse easily into pairs of friends, and many might be better examined by inviting a greater range of people into the interview. Although it is arguable this might lead to equally arbitrary cut off points being applied, it might nevertheless situate the participants' discourses within a more systemic context giving a better sense of the group processes involved.

This study specifically recruited gay men as opposed to bisexual men. Whilst a few male participants had some previous experience of heterosexual relationships and sexual behaviour, this was invariably constructed as occurring prior to their 'coming out' and adopting an exclusively gay identity. Thus it was strictly separated from their 
current identity and appeared to have no direct implications for their friendship.

In conclusion, some queer theorists have challenged sex as a defining element in the hierarchy of relationships. While this distinction remains, it is difficult to elevate friendship to equivalence with sexual relationships. Furthermore mixed-sex friends find themselves expected to explain the asexuality of their friendship as if romance were always preferable to friendship. Gay men's sexual identity may be a discursive resource for heterosexual women and gay men to partly legitimise their lack of desire, but this produces disclosure dilemmas and leaves unaddressed the imperative than under 'normal' circumstances emotionally close men and women should be romantically or sexually involved.

Consistent with Braun (2000), we found instances of sexist and heteronormative discourse spoken by 'liberal' people that may trouble the assumption that heterosexual women and gay men are 'natural' allies. Using Lorde's (1984) idea of the mythical norm, we have considered the difficulties in articulating forms of oppression that do not directly impinge upon the speaker's identity. Although this may be an inevitable difficulty for people speaking about different identities (including us as analysts), we found examples where friends who occupied different (non)normativities explored ways of challenging norms through the use of parody. We recognise that what looks like disruption of norms to queer theorists may be read as recapitulation by some feminist scholars. However, in the discourses presented parody seems to overlap with periodic inhabitation of norms, suggesting that queering and recapitulation may be less distinct than some theorists propose.

\section{REFERENCES}

Braun, V. (2000) 'Heterosexism in Focus Group Research: Collusion and Challenge', Feminism \& Psychology 10: 133-40.

Burr, V. (2003) Social Constructionism ( $2^{\text {nd }}$ ed). London: Routledge.

Butler, J. (1990) Gender Trouble: Feminism and the Subversion of Identity. London: Routledge.

Butler, J. (1993) Bodies that Matter: On the Discursive Limits of "Sex". London: Routledge.

D’Emilio, J. (1983) Sexual Politics, Sexual Communities: The Making of a Homosexual Minority in the United States, 1940-1970. Chicago: University of Chicago Press. 
Diamond, L.M. (2005) “I'm Straight, but I Kissed a Girl’: The Trouble with American Media Representations of Female-Female Sexuality’ Feminism \& Psychology 15: 104-10.

Edwards, D. and Potter, J. (1992) Discursive Psychology. London: Sage.

Frye, M. (1983) The Politics of Reality: Essays in Feminist Theory. New York: The Crossing Press.

'Help! I'm a Gay Man Trapped in a Woman's Body!' (2003) Elle, November, 131-2. Jackson, S and Scott, S. (2004) 'The Personal is still Political: Heterosexuality, Feminism and Monogamy' Feminism \& Psychology 14(1): 151-7. Jagose, A. (1996) Queer Theory: An Introduction. New York: New York University Press.

Jefferson, G. (2004) 'Glossary of Transcript Symbols with an Introduction', in G.H Lerner (ed.) Conversation Analysis: Studies from the First Generation, pp. 1331. Philadelphia, PA: John Benjamins.

Jeffreys, S. (1991) Anticlimax: a feminist perspective on the sexual revolution. New York: New York University Press.

Jeffreys, S. (2003) Unpacking Queer Politics: A Lesbian Feminist Perspective. Cambridge: Polity.

Kitzinger, C. and Perkins, R. (1993) Changing Our Minds: Lesbian Feminism and Psychology. London: Onlywomen Press.

Lamos, C. (1994) 'The Postmodern Lesbian Position: On Our Backs', in L. Doan (ed.) The Lesbian Postmodern, pp. 85-103. New York: Columbia University Press.

Lloyd, M. (1999) 'Performativity, parody, politics', Theory, Culture \& Society 16: 195-213.

Lorde, A. (1984) Sister Outsider: Essays and Speeches by Audre Lorde. Freedom, CA: The Crossing Press.

Nardi, P.M. (1999) Gay Men's Friendships: Invincible Communities. Chicago: University of Chicago Press.

Nentwich, J.C. (2008) 'New Fathers and Mothers as Gender Troublemakers? Exploring Discursive Constructions of Heterosexual Parenthood and their Subversive Potential', Feminism \& Psychology 18: 207-30.

Parker, I. (1992) Discourse Dynamics: Critical Analysis for Social and Individual Psychology. London: Routledge. 
Peel, E. (2005) 'Effeminate 'fudge nudgers' and tomboyish 'lettuce lickers':

Language and the construction of sexualities in diversity training', The Psychology of Women Section Review, 7 (2), 1-13.

Potter, J. and Hepburn, A. (2005) 'Qualitative Interviews in Psychology: Problems and

Possibilities', Qualitative Research in Psychology 2: 281-307.

Quimby, K. (2005) 'Will \& Grace: Negotiating (Gay) Marriage on Prime-Time

Television', The Journal of Popular Culture, 38 (4), 713-31.

Rich, A. (1980) 'Compulsory Heterosexuality and Lesbian Existence', Signs: Journal of Women in Culture and Society 5: 631-60.

Richardson, D. (1996) 'Heterosexuality and Social Theory', in D. Richardson (ed.) Theorising Heterosexuality: Telling it Straight, pp. 1-20. Buckingham: Open University Press.

Rose, S. (2000) 'Heterosexism and the Study of Women's Romantic and Friend Relationships', Journal of Social Sciences 56: 315-28.

Rubin, G. (1984) 'Thinking Sex: Notes for a Radical Theory of Politics of Sexuality', in C.S. Vance (ed.) Pleasure and Danger: Exploring Female Sexuality, pp. 267-319. London: Pandora Press.

Sandfield, A. and Percy, C. (2003) 'Accounting for Single Status: Heterosexism and Ageism in Heterosexual Women's Talk about Marriage', Feminism \& Psychology 13: 475-88.

Stokoe, E.H. and Weatherall, A. (2002) 'Gender, Language, Conversation Analysis and Feminism', Discourse \& Society 13: 707-13.

Valentine, G. (1993) '(Hetero)sexualising Space: Lesbian Perceptions and Experiences of Everyday Spaces', Environment and Planning: Society and Space 11: $395-$ 413.

Warner, M. (1993) Fear of a Queer Planet: Queer Politics \& Social Theory. Minneapolis, MN: University of Minnesota Press.

Warner, M. (1999) The Trouble with Normal: Sex, Politics and the Ethics of Queer Life. New York: Free Press.

Weeks, J. (1981) Sex, Politics and Society. The Regulation of Sexuality since 1800, London: Longman Press.

Werking, K.J. (1997) 'Cross-sex friendship research as ideological practice', in S. Duck (ed.) Handbook of Personal Relationships ( $2^{\text {nd }}$ ed), pp. 391-410. New York: John Wiley \& Sons. 
Wetherell, M. (1998) 'Positioning and Interpretative Repertoires: Conversation Analysis and Post-structuralism in Dialogue', Discourse \& Society 9: 387-412. Willig, C. (2001) Introducing Qualitative Research in Psychology: Adventures in Theory and Method, Buckingham: Open University Press.

Dan SHEPPERD is a PhD candidate in the Department of Psychology at the University of Surrey. His research interests include discourses of gender and sexuality in constructions of friendship.

ADDRESS: Department of Psychology, University of Surrey, Guildford, Surrey GU2 7XH, UK.

[email: D.Shepperd@surrey.ac.uk]

Adrian COYLE is a Senior Lecturer in the Department of Psychology at the University of Surrey, where he is Director of the MSc Programme in Social Psychology. His research and publications have addressed a range of topics, including various issues within lesbian and gay psychology. With Evanthia Lyons, he is coeditor of Analysing Qualitative Data in Psychology (Sage, 2007).

ADDRESS: Department of Psychology, University of Surrey, Guildford, Surrey GU2 $7 \mathrm{XH}, \mathrm{UK}$.

[email: A.Coyle@surrey.ac.uk]

Peter HEGARTY is a Social Psychologist and a Historian of Psychology and Senior Lecturer in the Department of Psychology at the University of Surrey. His work in both history and social psychology focuses on the operations of normativity with particular reference to scientific discourses about group identity and difference. ADDRESS: Department of Psychology, University of Surrey, Guildford, Surrey GU2 $7 \mathrm{XH}, \mathrm{UK}$.

[email: P.Hegarty@surrey.ac.uk] 